\title{
Peculiarities of interpersonal relationships of Ukrainian Antarctic expeditions participants
}

\author{
Larysa Bakhmutova
}

National Antarctic Scientific Center, Ministry of Education and Science of Ukraine, Kyiv, Ukraine

\section{Abstract}

Introduction: Extreme conditions of the Antarctic environment is affected both on the psychophysiological state of peoples and interpersonal relationships in a small group of winterers.

Purpose: To determinate the peculiarities of interpersonal relations in an isolated small group of winterers of Ukrainian Antarctic expeditions

Methodology: The study was conducted by diagnostic Technique for interpersonal relationships T. Leary for self-assessment of behavior (Leary, 1957). The predominant type of relations in the group of winterers was revealed as a component of interpersonal interaction. Monitoring was carried out in the last three years in the dynamics of "before" and "after" the expedition.

Results and Discussion: The study identified the relationship of "dominance" prevails in $70 \%$ of winterers before the expedition and increases to $84 \%$ on the end of expedition. $73 \%$ of winterers to establish friendly relations and cooperation. However, we observe a transition from friendliness at the beginning of the expedition to a gradual increase in aggression in interpersonal relationships after returning from the expedition by $17 \%$. During the expedition (in the dynamics) we observed a gradual decrease in the average indicators of "subordination" and "dependence" as factors of interpersonal relations "dominance" and "aggression". There significant inverse correlation between the level of adaptation to the extreme conditions of Antarctica and the dependent type of relationship ( $r=-0.63 * ; p=0.04$ ). According to the expert assessment, such people have problem with adaptation to the environment of Antarctica and could be complicated relations and interaction in an isolated group of winterers.

Conclusions: 1) The "friendliness" and "dominance" are the predominant type of relationship in a small group of winterers: 2) The authoritarianism, aggression, selfishness and dependence are the inadmissible and undesirable types of interpersonal relations in extreme conditions of relative isolation on the Antarctic station

\section{Keywords}

Antarctica, winterers, extreme conditions, mental health, well-being, interpersonal relationships, socio-spatial isolation in a small group, psychophysiological and emotional changes.

\section{Address for correspondence:}

Larysa Bakhmutova, Ph.D., National Antarctic Scientific Center, Ministry of Education and Science of Ukraine, Kyiv, Ukraine. e-mail bakhml@meta.ua

This work is licensed under a Creative Commons Attribution-

NonCommercial 4.0 International License (CC BY-NC 4.0).

\section{(c) (i) (9)}

(c) Copyright: Bakhmutova, 2020

Submitted for publication: 17 July 2020

Received: 17 July 2020 Accepted for publication: 30 October 2020 


\section{Introduction}

Ukraine as a member of the Antarctic Treaty and in the framework of fulfilling international obligations every year sends the wintering team to Ukrainian Antarctic station "Akademik Vernadsky". The 11-12 specialists of various profiles are keeps the annual operation and scientific investigation on the station. Well known that the long stay in extreme natural conditions leads to psychophysiological and emotional changes of peoples. The professional activity of Ukrainian winterers performs on the Akademik Vernadsky station during a long time (12-13 months) in social isolation in a small group. As a result, the gradual narrowing of social contacts and disruption of interpersonal relationships lead to physiological and psychological neurosis in a small group. Continuously communicating with the same members of team, each individual has by a poverty of sensory stimuli and a paucity of perceptual, communicative and interactive actions.

Thus over time the emotional tension, inadequacy of perception, reduced tolerance and grown of conflicts begins to manifest in interpersonal relationships (Bakhmutova, 2019, May; Bakhmutova, 2019; Kokun, \& Bakhmutova, L. 2020; Palinkas, \& Suedfeld, 2008).

The instability of relationships is the main peculiarity of the dynamics of group's processes in long-term social and limited by area isolation of team members. Sometimes the relationships going to more complicated and conflicts are arise. The significant changes in morals and characters of interpersonal relationships in the case of group isolation note in (Pagel, \& Choukèr, 2016).

Many researchers, e.g. Kokun, \& Shamich, (2016); Mullin (2006); Palinkas, \& Suedfeld (2008); Pagel, \& Choukèr (2016); Roberts (2011) etc., are reveal a whole range of psychophysiological reactions inherent of people during the isolation. These are increased irritability, which sometimes turns into short-term outbursts of anger, sleep disturbances, headaches, general malaise, fatigue, low mood, cognitive decline, nostalgia, pessimism, suspicion, alertness, anxiety, mood swings, aloofness, social isolation.

In some papers, e.g. Khandelwal, Bhatia, \& Mishra (2017); Sandal, Leon, \& Palinkas (2006); Smith, Kinnafick, \& Saunders (2017), the authors are note an increase in introversion, neuroticism, depression, anxiety and decrease in leadership and dominance. All this can affect the disruption of interpersonal interaction in a small group. As a results the errors in extreme situations, conflicts both within the isolated group and in relations with main department science and management and so on. This significantly affects the behavior, performance, interpersonal interaction and efficiency of the whole team. Almost all the presented characteristics are confirmed by the vast majority of doctors of various Antarctic expeditions.

Among the huge variety of negative reactions to isolation Strange, \& Klein (1973) stressed attention in symptoms of "Antarctic" or "wintering syndrome": depression, hostility, suspicion, sleep disturbances and cognitive impairment.

There are a very few socio-psychological studies of group phenomenon in isolation. They stress attention to study the relationships and compatibility in isolated small groups and necessity to study the characteristics of these groups. These studies are often descriptive and based on data from uncontrolled observation of groups in experimental or natural conditions.

The changes in psychological state and behavioral patterns are due to Separation from the wider social environment, the necessity to adaptation in a small isolated group and lack of many conventional sources of emotional satisfaction Mullin (2006); Norris, Paton, \& Ayton (2010).

Ukrainian winterers of various polar expeditions testify to the consequences of social isolation, such as personal crises associated with the illness or death of a family member or loved one, the deterioration of marital relations, problems with raising children due to prolonged separation. In addition, tensions and conflicts in the winter team are caused by misunderstandings with "external" management departments and agencies due to unsuccessful intervention in the rules at the station, delays logistics operations with wintering crew changing, problems with misinterpretation of official massages from Center, alarming news from Ukraine etc. In many expeditions wintering staff have often reported about problems from mood swings and anxiety to more severe psychiatric reactions. These changes are particularly pronounced within the polar winter and they coincide with the symptoms known as the "Antarctic syndrome".

Thus the social isolation significantly affects the psychological health of staff working in sociospatial isolation and is a significant external factor in peculiarity of professional interaction in a small group. This is manifested through changes in the psychophysiological, emotional, social and professional areas. 


\section{Purpose}

To determinate the peculiarities of interpersonal relations in an isolated small group of winterers of Ukrainian Antarctic expeditions.

\section{The main objectives:}

1) to identify the predominant type of relationship in a small group of winterers.

2) to identify unacceptable (undesirable) in terms of socio-spatial isolation types of interpersonal relationships.

\section{Methodology}

The study was conducted by diagnostic Technique for interpersonal relationships T. Leary for self-assessment of behavior (Leary, 1957). The predominant type of relations in the group of winterers was revealed as a component of interpersonal interaction. Monitoring was carried out in the last three years in the dynamics of "before" and "after" the expedition. The study of voluntary consent involved 36 members (male) of three Ukrainian Antarctic expeditions aged of 23 to 63-year-old. SPSS 22.0.0 programming package was used for statistical analysis. Paired Sample T-Test was used. The data obtained in research have the normal distribution of studied data (One-Sample Kolmogorov-Smirnov Test).

\section{Results and Discussion}

The study identified the predominant personality types for each member of wintering teams: I - Authoritarian; II - Selfish; III Aggressive; IV - Suspicious; V - Subordinate; VI Dependent; VII - Friendly; VIII - Altruistic. According to special formulas, indicators are determined by the main factor: 1) dominancesubordination; 2) friendliness- aggression

According to the factors of "dominancesubordination" the statistical processing of interpersonal relations indicators in three teams of winterers was carried out.

The results obtained by this factors show that the relationship of "dominance" prevails in $70 \%$ of winterers before the expedition and increases to $84 \%$ on the end of expedition.

The results of the formula "friendliness" are an indicator of the desire of $73 \%$ of winterers to establish friendly relations and cooperation.

However, we observe a transition from friendliness at the beginning of the expedition to a gradual increase in aggression in interpersonal relationships after returning from the expedition by 17\% (Table 1).
Table 1 Distribution of indicators of interpersonal relations among UAE winterers

\begin{tabular}{|c|c|c|c|c|c|c|c|c|}
\hline \multirow[t]{2}{*}{ № } & \multirow[t]{2}{*}{$\begin{array}{l}\text { Indicators of } \\
\text { interpersonal } \\
\text { relationships }\end{array}$} & $\begin{array}{l}\bar{\Phi} \\
\frac{\Omega}{\varepsilon}\end{array}$ & \multicolumn{2}{|c|}{$\begin{array}{l}\text { Before the } \\
\text { expedition }\end{array}$} & \multicolumn{2}{|c|}{$\begin{array}{l}\text { After the } \\
\text { expedition }\end{array}$} & \multicolumn{2}{|c|}{$\begin{array}{c}\text { Deviation } \\
(+;-)\end{array}$} \\
\hline & & $n$ & $\mathrm{nl}$ & $\%$ & $\mathrm{n} 2$ & $\%$ & $\begin{array}{l}\mathrm{n} 2- \\
\mathrm{n} 1\end{array}$ & $\%$ \\
\hline \multirow{2}{*}{1} & dominance & \multirow{2}{*}{36} & 25 & 70 & 30 & 84 & +5 & +14 \\
\hline & subordination & & 11 & 30 & 6 & 16 & -5 & -14 \\
\hline \multirow{2}{*}{2} & friendliness- & \multirow{2}{*}{36} & 26 & 73 & 20 & 56 & -6 & -17 \\
\hline & aggression & & 10 & 27 & 16 & 44 & +6 & +17 \\
\hline
\end{tabular}

This data is confirmed by detailed study of personality types in a separate small group of winterers consisting of 12 people. We provided three examinations: 1 - before expedition; 2 - on the middle of winter; 3 - after returning from Antarctica. There is a decrease in the level of average indicators (M) of two types of personality: "subordinate" and "dependent".

General decreas of subordination level and an increase of dominance level in group are precisely due to reduction of "subordinate" and "dependent" (Table 2).

Table 2 Analysis of the dynamics of indicators of personality types in the group

\begin{tabular}{|c|l|c|c|c|c|c|c|}
\hline \multirow{2}{*}{ № } & \multirow{2}{*}{$\begin{array}{c}\text { Personality } \\
\text { types }\end{array}$} & \multicolumn{3}{|c|}{ Research 1 } & \multicolumn{2}{c|}{ Research 2 } & \multicolumn{2}{c|}{ Research 3 } \\
\cline { 3 - 8 } & & $\mathrm{M} 1$ & $\sigma 1$ & $\mathrm{M} 2$ & $\sigma 2$ & $\mathrm{M} 3$ & $\sigma 3$ \\
\hline 1 & subordinate & 4,75 & 2,26 & 4,82 & 2,52 & 3,82 & 1,54 \\
\hline 2 & dependent & 5,25 & 2,13 & 3,73 & 2,79 & 3,55 & 1,57 \\
\hline & $\mathrm{P} \leq$ & 0.05 & & 0.05 & & 0.05 & \\
\hline
\end{tabular}

and lowest average values of each indicator.

During the expedition (in the dynamics) we observed a gradual decrease in the average indicators (M) of "subordination" and "dependence" as factors of interpersonal relations "dominance" and "aggression". A decrease in the level of "subordination" and "dependence" leads to an increase in the level of dominance in the group.

Interpersonal interaction of winterers of Ukrainian Antarctic expeditions in extreme nature conditions and internal isolation in a small group takes place in three areas: professional, domestic and leisure. The results of Spearman's correlation are shown of reliable inverse correlation coefficients of "authoritarian" ( $r=-38 * ; r=0.02)$, 
"egoistic" ( $r=0.35 * ; r=0.04)$ and "aggressive" type of relations in professional relationships of interpersonal interaction.

In domestic relations the aggressive type of relationship is unacceptable $(r=-0.62 ; \mathrm{p}=$ 0.04 ). In the leisure area the authoritarian type of relations is dominates $(r=-0.48 * * ; p=0.00)$ (Table. 3). The rejection of authoritarian and selfish types of relations is normally for the first half of the winter period (R1 - April-May; R2 - JuneSeptember). This is explained by establishing of interpersonal relations in a socially isolated group of winterers.

Professional activities are quite busy at this time due to short term stay at the station. Therefore, at this period, the own type of strong personality (leader) may appear in any member. At the same time the rest of the winterers remain dissatisfied. In the leisure area the most acutely perceived the authoritarian type of relationship during the "polar night" when the professional activity is stabilized and even decreases. Here the leisure and daily life are preferred.

Table 3. Correlation of types of relationships in the areas of interpersonal interaction

\begin{tabular}{|c|c|c|c|c|}
\hline \multirow{2}{*}{$\begin{array}{l}\frac{0}{\frac{1}{0}} \\
\frac{c}{0} \\
0\end{array}$} & \multirow{2}{*}{$\begin{array}{l}\frac{c}{0} \\
\bar{D} \\
\mathbb{D} \\
\mathscr{Q} \\
\widetilde{Q}\end{array}$} & \multicolumn{3}{|c|}{ Types of relationships } \\
\hline & & Authoritarian & Selfish & Aggressive \\
\hline \multirow{4}{*}{ 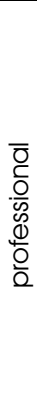 } & R1 & $\begin{array}{l}r=-0,38^{*} \\
p=0,02\end{array}$ & $\begin{array}{l}r=-0,26 \\
p=0,14\end{array}$ & $\begin{array}{l}r=-0,16 \\
p=0,36\end{array}$ \\
\hline & R2 & $\begin{array}{l}r=-0,23 \\
p=0,17\end{array}$ & $\begin{array}{l}r=-0,35^{*} \\
p=0,04\end{array}$ & $\begin{array}{l}r=-0,21 \\
p=0,22\end{array}$ \\
\hline & R3 & $\begin{array}{l}r=-0,37 \\
p=0,27\end{array}$ & $\begin{array}{l}r=-0,45 \\
p=0,16\end{array}$ & $r=-0,59 ; p=0,06$ \\
\hline & R4 & $\begin{array}{l}r=-0,58 \\
p=0,06\end{array}$ & $\begin{array}{l}r=-0,35 \\
p=0,29\end{array}$ & $\begin{array}{l}r=-0,64^{*} \\
p=0,03\end{array}$ \\
\hline \multirow{4}{*}{ 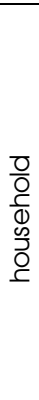 } & R1 & $\begin{array}{l}r=0,01 \\
p=0,99\end{array}$ & $\begin{array}{l}r=0,01 \\
p=0,95\end{array}$ & $r=-0,08 ; p=0,64$ \\
\hline & R2 & $\begin{array}{l}r=-0,26 \\
p=0,13\end{array}$ & $\begin{array}{l}r=-0,16 \\
p=0,35\end{array}$ & $r=0,05 ; p=0,77$ \\
\hline & R3 & $\begin{array}{l}r=0,07 \\
p=0,84\end{array}$ & $\begin{array}{l}r=-0,22 \\
p=0,51\end{array}$ & $r=-0,23 ; p=0,50$ \\
\hline & R4 & $\begin{array}{l}r=-0,28 \\
p=0,41\end{array}$ & $\begin{array}{l}r=-0,43 \\
p=0,18\end{array}$ & $\begin{array}{l}r=-0,62^{*} \\
p=0,043\end{array}$ \\
\hline
\end{tabular}

\begin{tabular}{|c|c|c|c|c|}
\hline \multirow{4}{*}{ 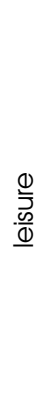 } & R1 & $\begin{array}{l}r=-0,22 ; p= \\
0,20\end{array}$ & $\begin{array}{l}r=-0,15 \\
p=0,38\end{array}$ & $r=-0,05 ; p=0,77$ \\
\hline & $\bar{R} 2$ & $\begin{array}{l}r=-0,48^{* *} ; \\
p=0,00\end{array}$ & $\begin{array}{l}r=-0,08 \\
p=0,67\end{array}$ & $r=-0,04 ; p=0,81$ \\
\hline & R3 & $\begin{array}{l}r=0,22 \\
p=0,51\end{array}$ & $\begin{array}{l}r=0,21 ; p \\
=0,55\end{array}$ & $r=0,54 ; p=0,08$ \\
\hline & $\overline{\mathrm{R} 4}$ & $\begin{array}{l}r=-0,58 \\
p=0,06\end{array}$ & $\begin{array}{l}r=-0,10 \\
p=0,77\end{array}$ & $r=-0,37 ; p=0,25$ \\
\hline
\end{tabular}

Note: Correlation is significant at the level of $p$ * $\leq 0.05$ (bilateral)

(bilateral)

Correlation is significant at the level of $p * * \leq 0.01$

Aggressive type of relations is especially unacceptable in the professional $(r=-0.64 * ; p$ $=0.03)$ and domestic $(r=-0.62 * ; p=0.04)$ areas. This rejection is clearly manifested at the end of winter (R4 - January-March), when physical and psychological fatigue begin to predominate. Hence the vigilant, aggressive, and sometimes hostile relation may occur. Such relationships can lead to antisocial behavior in extreme cases (Table 3).

Correlation analysis (according to Spearman) of the types of relations with the expedition leader assessment revealed a significantly high feedback of the aggressive type of relations to the level of adaptation of winterers for polar conditions $(r=-0.83 * * ; p=0.00)$ and to the level of professional satisfaction $(r=-0.63 * ; p=$ $0.03 ; r=-0.62 * ; p=0.04$ ). This is confirming the inadmissibility of an aggressive type of relationship in the team of winterers (Table 4).

Table 4. Inverse correlations of expert (head of expedition) assessment of types of winterers relationships

\begin{tabular}{|l|l|l|}
\hline \multirow{2}{*}{$\begin{array}{c}\text { Types of } \\
\text { relationships }\end{array}$} & \multicolumn{2}{|c|}{ "r" та "p" with expert assessment } \\
\cline { 2 - 3 } & $\begin{array}{c}\text { level of } \\
\text { adaptation to } \\
\text { polar conditions }\end{array}$ & $\begin{array}{c}\text { level of satisfaction } \\
\text { with professional } \\
\text { activity }\end{array}$ \\
\hline aggressive & $\begin{array}{l}r=-0,83^{* *} ; \\
p=0,00\end{array}$ & $\begin{array}{l}r \quad=-0,63^{*} ; \\
p=0,03\end{array}$ \\
\hline dependent & $\begin{array}{l}r=-0,67^{*} ; \\
p=0,04\end{array}$ & $r=-0,55 ; p=0,08$ \\
\hline
\end{tabular}

Note: Correlation is significant at the level of $p$ * $\leq 0.05$ (bilateral) (bilateral).

Correlation is significant at the level of $p^{* *} \leq 0.01$

The significant inverse correlation between the level of adaptation to the extreme conditions of 
Antarctica and the dependent type of relationships was revealed $(r=-0.63 * ; p=$ 0.04 ), Table 4 . The insecure person with obsessive fears and anxieties due to any reasons is unable to resist of own emotions. According to the expert assessment such persons have a problem with adaptation to Antarctica surrounding and could be complicated relations and interaction in an isolated group of winterers

\section{Conclusions}

Thus, the assembling of winterers team is requiring a significant advantage in terms of "friendliness" and "dominance" types of relationships. Maintaining the level of friendliness in the team until the end of winter is an important direction of psychological work with the team throughout the expedition. It is revealed that the main attention of winterers and the expedition leader is concentrated on inadmissible and undesirable types of interpersonal relations in extreme conditions of relative isolation. There is authoritarianism, aggression, selfishness and dependence. It is necessary to pay attention for diagnostic and detection of persons with these behaviors on the stage of psychological selection and preparation of the team for wintering in Antarctica.

\section{Conflict of interest}

The author declares that she has no conflict of interests

\section{References}

Bakhmutova, L. (2019, May). Dynamics of the selfconception of the psychological state of the Ukrainian Antarctic Expeditions participants. IX International Antarctic Conference Dedicated to the 60th anniversary of the signing of the Antarctic Treaty in the name of peace and development of international cooperation (pp. 203-204). Kyiv, http://uac.gov.ua/internationalcooperation/mak/mak-2019/

Bakhmutova, L. (2019). Factors and models of interpersonal interaction of participants in long-term Ukrainian Antarctic Expeditions. Fundamental and applied research in practice of leading scientific schools, 36(6), 48-55.

https://doi.org/10.33531/farplss.2019.6.6

Kokun, O., \& Bakhmutova, L. (2020). Dynamics of Indicators of Expeditoners' Psychological States During Long Antarctic Stay. International
Journal of Psychology and Psychological Therapy, 20(1), 5-12. https://www.ijpsy.com/volumen20/num1/530.ht $\mathrm{ml}$

Kokun, O. M. \& Shamich, O. M. (2016). Psychological characteristics of Paralympic athletes' self-realisation. Social Welfare. Interdisciplinary Approach, 6(2), 138-147. http://socialwelfare.eu/index.php/sw/article/vie $\mathrm{w} / 273$

Leary, T. (1957). Interpersonal Diagnosis of Personality: A Functional Theory and Methodology for Personality Evaluation. New York: John Wiley \& Sons.

Khandelwal S. K., Bhatia A., \& Mishra A. K. (2017). Psychological Adaptation of Indian Expeditioners During Prolonged Residence in Antarctica. Indian Journal of Psychiatry, 59(3), 313-319.

http://www.indianjpsychiatry. org/article.asp?iss $\mathrm{n}=0019$ 5545; year $=2017$; volume $=59 ;$ issue $=3$; spage $=313$; epage $=319$; aulast $=$ Khandelwal

Mullin, JR. (2006). Some Psychological Aspects of Isolated Antarctic Living. American Journal of Psychiatry 117(4), 323-325. 10.1176/ajp. 117.4.323

Norris, K., Paton, D., \& Ayton, J. (2010). Future directions in Antarctic psychology research. Antarctic Science, 22(04), 335-342. $10.1017 /$ s0954102010000271

Pagel, J. I. \& Choukèr, A. (2016). Effects of isolation and confinement on humansimplications for manned space explorations. Journal of Applied Physiology, 120(12), 14491457 ,

https://journals. physiology.org/doi/pdf/10.1 152/ japplphysiol.00928.2015

Palinkas, L. A., \& Suedfeld, P. (2008). Psychological effects of polar expeditions. The Lancet, 371(9607), 153-163.

Scott, R. F. (1972). «Terra Nova» Expedition to the Antarctic, 1910-1912: An account of Scott's last expedition. Hardcover: Blandford Press.

Roberts, R. (2011). Psychology at the end of the world. The Psychologist. British Psychological Society, 24 (1), 22-25.

Sandal, G. M., Leon, G., \& Palinkas, L. (2006). Human challenges in polar and space environments. Environmental Science and Biotechnology, 5(2-3), 281-296.

Smith, N., Kinnafick, F., \& Saunders, B. (2017). Coping Strategies Used During an Extreme Antarctic Expedition. Journal of Human Performance in Extreme Environments, 13(1), Article 1. Doi: 10.7771/2327-2937.1078 
Strange, R. \& Klein, W. (1973). Emotional and social adjustment of resent us winter-over parties in isolated Antarctic Station. The Proceedings of the SCAR/IUPS/IUBS Symposium on Human Biology and Medicine in the Antarctic, 410-416. https://doi.org/10.1016/B978-0-433-081555.50043-1 